\title{
Antitumor Activity of Arsenic Trioxide on Retinoblastoma: Cell Differentiation and Apoptosis Depending on Arsenic Trioxide Concentration
}

\author{
Jeong Hun Kim, ${ }^{1,2,3}$ Jin Hyoung Kim, ${ }^{1,2,3}$ Young Suk Yu, ${ }^{1,2}$ Dong Hun Kim, \\ Chong Jai Kim, ${ }^{5}$ and Kyu-Won Kim ${ }^{6}$
}

Purpose. Arsenic trioxide (ATO) targets multiple pathways in malignant cells, resulting in the promotion of differentiation or in the induction of apoptosis. The antitumor activity of ATO on retinoblastoma was investigated.

Methods. Human retinoblastoma cells were incubated with various ATO concentrations. The antiproliferative effect of ATO was evaluated by 3-(4,5-dimethylthiazol-2-yl)-2,5-diphenyltetrazolium bromide assay, and the effect of ATO on cellcycle progression was validated by flow cytometry. At a low concentration, the ATO-induced differentiation of retinoblastoma cells was evaluated by neurofilament expression and extracellular signal-regulated kinase (ERK)1/2 activation, which was confirmed by the inhibition of ERK1/2. At a high concentration, ATO-induced $\mathrm{H}_{2} \mathrm{O}_{2}$ production was investigated with the cell-permeable fluorescent dye $2^{\prime} 7^{\prime}$-dichlorofluorescein-diacetate, and the relationship of ATO-induced $\mathrm{H}_{2} \mathrm{O}_{2}$ production with caspase-3-dependent apoptosis was validated by Western blot and 4'6-diamidino-2-phenolindole staining, which wwas confirmed by reactive oxygen species (ROS) inhibition. The effect of ATO on tumor formation was assessed with an orthotopic animal model of retinoblastoma.

RESulTs. The antitumor activity of ATO in retinoblastoma was related to two main mechanisms, differentiation and apoptosis, which were determined by the level of ATO. At a low dose $(\leq 1$ $\mu \mathrm{M})$, ATO induced the differentiation of retinoblastoma cells through ERK1/2 activation, whereas ROS generation by a high dose $(\geq 2 \mu \mathrm{M})$ of ATO induced apoptosis in retinoblastoma cells. Moreover, ATO at low and high doses effectively inhibited tumor formation.

Conclusions. These results suggest that ATO can be used as an effective alternative therapeutic for the treatment of retinoblastoma. (Invest Opbthalmol Vis Sci. 2009;50: 1819-1823) DOI:10.1167/iovs.08-2623

From the Departments of ${ }^{1}$ Ophthalmology and ${ }^{5}$ Pathology, Seoul National University College of Medicine, Seoul, Korea; ${ }^{2}$ Seoul Artificial Eye Center, Clinical Research Institute, Seoul National University Hospital, Seoul, Korea; ${ }^{4}$ Department of Radiology, College of Medicine, Soonchunhyang University, Bucheon, Korea; and the ${ }^{6}$ Neurovascular Coordination Research Center, College of Pharmacy and Research Institute of Pharmaceutical Sciences, Seoul National University, Seoul, Korea.

${ }^{3}$ These authors contributed equally to the work presented here and should therefore be regarded as equivalent authors.

Supported by Grant 800-20080680 from the National Research and Development Program for Cancer Control, Ministry of Health and Welfare, Republic of Korea.

Submitted for publication July 26, 2008; revised September 25, and November 17 and 18, 2008; accepted February 9, 2009.

Disclosure: J.Hu. Kim, None; J.Hy. Kim, None; Y.S. Yu, None; D.H. Kim, None; C.J. Kim, None; K.-W. Kim, None

The publication costs of this article were defrayed in part by page charge payment. This article must therefore be marked "advertisement" in accordance with 18 U.S.C. $\$ 1734$ solely to indicate this fact.

Corresponding author: Young Suk Yu, Seoul Artificial Eye Center Clinical Research Institute, Seoul National University Hospital, Yongondong, Chongno-gu, Seoul 110-744, Republic of Korea; ysyu@snu.ac.kr.
$\mathbf{R}$ etinoblastoma is the most common intraocular cancer in children. ${ }^{1}$ Treatment options, including enucleation, radiation, and chemotherapy and additional focal treatments with cryotherapy, laser photocoagulation, and thermotherapy, have saved patients' lives, producing an overall survival rate of $90 \%$ to $95 \% .^{2}$ Although enucleation and radiotherapy are still used for retinoblastoma, systemic chemotherapy has been gradually used to avoid radiotherapy and enucleation. Recently, chemotherapy combined with focal treatments has improved the rate of eye salvage or vision preservation. ${ }^{3,4}$ The current chemotherapy regimen for retinoblastoma is based on carboplatin and etoposide, which were originally used to treat other rare childhood solid cancers of the central nervous system. ${ }^{5}$ However, alternative chemotherapeutic combinations have not been identified. Moreover, etoposide has been known to increase acute myeloblastic leukemia as a secondary malignancy, likely because of its topoisomerase II inhibitory effect. ${ }^{6}$ In the course of our research on alternative chemotherapeutics for retinoblastoma, we recently showed that arginine deprivation by arginine deaminase could be another treatment option for retinoblastoma because of the low activity of argininosuccinate synthetase in retinoblastoma cells. ${ }^{7,8} \mathrm{New}$ chemotherapy protocols for retinoblastoma should be further investigated.

Arsenicals have a long history of use in the treatment of leukemia, and arsenic trioxide (ATO) has been used primarily in the treatment of acute promyelocytic leukemia (APL). ${ }^{9}$ Interestingly, to date, there is little evidence that the development of resistance to chemotherapy could affect its efficacy. Although it is not fully understood how ATO mediates its clinical efficacy, it has been determined that ATO targets multiple pathways, including intracellular glutathione and $\mathrm{H}_{2} \mathrm{O}_{2}$ levels in malignant cells, resulting in the promotion of differentiation or in the induction of apoptosis. ${ }^{10}$ Actually, ATO has been used to treat hematologic malignancies, including acute non-APL myeloid leukemia, acute lymphocytic leukemia, chronic myelogenous leukemia, low-, intermediate-, and high-grade non-Hodgkin's lymphoma, Hodgkin's disease, chronic lymphocytic leukemia, multiple myeloma, and solid tumors of the prostate, kidney, cervix, and bladder. ${ }^{11}$ ATO-induced differentiation in APL is caused by the degradation of promyelocytic leukemia protein (PML)-retinoic acid receptor (RAR)- $\alpha$, whereas ATO-induced apoptosis occurs independently of the presence of PML-RAR$\alpha,{ }^{12,13}$ which suggests that ATO may be effective in the treatment of a variety of malignancies. Recently, we showed that ATO has therapeutic potential for peripheral primitive neuroectodermal tumor through differentiation mediated by extracellular signal-regulated kinase (ERK) $1 / 2$ and apoptosis with the activation of $c$-Jun $N$-terminal kinase. ${ }^{14}$ Retinoblastoma shares phenotypic similarities with neuroblastoma, which has been proved by morphologic, cytogenetic, immunohistochemical, biochemical, and in vitro studies. ${ }^{15,16}$

In our study, we demonstrated that ATO can have antitumor activity for retinoblastoma. The antitumor activity of ATO in retinoblastoma was related to two main mechanisms of action of ATO, differentiation and apoptosis, which were determined by ATO level. At a low dose $(\leq 1 \mu \mathrm{M})$, ATO induced the 
differentiation of retinoblastoma cells through ERK1/2 activation, whereas reactive oxygen species (ROS) generation produced by a high dose $(\geq 2 \mu \mathrm{M})$ of ATO induced apoptosis in retinoblastoma cells. Moreover, ATO at low and high doses effectively inhibited tumor formation in experimental animal models of retinoblastoma, which our group had already established. ${ }^{17}$ We suggest that ATO has therapeutic potential in the treatment of retinoblastoma through differentiation and apoptosis, depending on the concentration used.

\section{Materials ANd Methods}

\section{Retinoblastoma Cells}

Human retinoblastoma cell line Y79 (American Type Culture Collection, Rockville, MD) and SNUOT-Rb1, a novel human retinoblastoma cell line with different characteristics of adherent growth and chromosomal imbalances from those of Y79 or WERI-RB1, established by our group,${ }^{17}$ were maintained in RPMI 1640 media (WelGENE, Daegu, Korea), supplemented with $10 \%$ fetal bovine serum (Gibco BRL, Rockville, MD) and $1 \%$ antibiotic-antimycotic solution (Invitrogen, Carlsbad, CA) at $37^{\circ} \mathrm{C}$ in a moist atmosphere of $95 \%$ air and $5 \% \mathrm{CO}_{2}$. The medium was changed every third day. Cultured tumor cells were observed daily under a phase-contrast microscope (Carl Zeiss, Chester, VA).

\section{Animals}

BALB/c-nude mice were purchased from Samtako (Osan, Korea). Care, use, and treatment of all animals in this study were in strict accordance with the ARVO Statement for the Use of Animals in Ophthalmic and Vision Research. C57BL/6 mice were kept under a standard 12-hour light/12-hour dark cycle and in a room with an approximate temperature of $23^{\circ} \mathrm{C}$.

\section{Cell Growth Assay}

Cell growth assay was carried out using 3-(4,5-dimethylthiazol-2-yl)-2,5diphenyltetrazolium bromide (MTT) assay. Retinoblastoma cells $(1 \times$ $10^{7}$ ) were seeded in 12-well culture plates and treated with various concentrations of ATO (range, $0.1-10 \mu \mathrm{M}$ ) for 72 hours. The medium was then replaced with fresh medium containing $0.5 \mathrm{mg} / \mathrm{mL}$ MTT and left for 4 hours. After incubation, the medium was carefully removed from the plate, and dimethyl sulfoxide was added to solubilize formazan produced from MTT by the viable cells. Absorbance was measured at $540 \mathrm{~nm}$ using a microplate reader (Molecular Devices, Sunnyvale, CA).

\section{Cell-Cycle Analysis by Flow Cytometry}

Retinoblastoma cells were seeded in a $60-\mathrm{mm}$ dish $\left(5 \times 10^{5}\right.$ cells $)$ and incubated for 24 hours. For synchronization purposes, the cells were starved for 16 hours. They were then treated with various concentrations of ATO (range, 0.1-10 $\mu \mathrm{M}$ ), harvested, and fixed in $70 \%$ ethanol. Before analysis, cells were washed with phosphate-buffered saline (PBS) and resuspended in PBS ( $\mathrm{pH} 7.4)$. RNase $(80 \mu \mathrm{g} / \mathrm{mL})$ and propidium iodide $(50 \mu \mathrm{g} / \mathrm{mL})$ were added to the suspended cells and left for 1 hour. DNA histograms were determined with a flow cytometer system (FACS Vantage; Becton Dickinson, San Jose, CA).

\section{Western Blot Analysis}

Western blot analysis was performed using standard Western blot methods and visualized after image development (LAS-3000; Fujifilm, Tokyo, Japan). The protein concentration was measured with a bicinchoninic acid protein assay kit (Pierce, Rockford, IL). Immunoblotting was performed with primary antibodies against neurofilament (Santa Cruz Biotechnology, Santa Cruz, CA), phospho-ERK1/2, ERK1/2, cleaved caspase-3, or caspase-3 (Cell Signaling Technology, Beverly, MA). To ensure the equal loading of protein in each lane, the blots were stripped and reprobed with an antibody against $\beta$-tubulin.

\section{$\mathrm{H}_{2} \mathrm{O}_{2}$ Production}

Retinoblastoma cells were treated with $10 \mathrm{mM}$ of $N$-acetylcysteine (NAC) 1 hour before treatment with $5 \mu \mathrm{M}$ ATO. After 6 hours of treatment with $\mathrm{As}_{2} \mathrm{O}_{3}$, cells were labeled with $20 \mu \mathrm{M}$ of $2^{\prime}, 7^{\prime}$-dichlorofluorescein-diacetate ( $2^{\prime}, 7^{\prime}$-DCFH-DA; Sigma-Aldrich, St. Louis, MO) for 30 minutes at $37^{\circ} \mathrm{C}$. The ROS-oxidized form of DCFH-DA was measured using fluorescence microscopy (BX50; Olympus, Tokyo, Japan) with excitation and emission settings of 495 and $525 \mathrm{~nm}$, respectively.

\section{4',6-Diamidino-2-Phenolindole Staining}

We conducted $4^{\prime}$,6-diamidino-2-phenolindole (DAPI) staining for the identification of apoptotic nuclei. Retinoblastoma cells in 12-well plates were treated with $10 \mathrm{mM}$ NAC or $5 \mu \mathrm{M}$ ATO and then were washed twice in ice-cold PBS (pH 7.3) and fixed in 1\% paraformaldehyde for 10 minutes at room temperature. After fixation, cells were washed three times with washing buffer $(0.1 \%$ Triton X-100 in PBS; $\mathrm{pH}$ 7.3) and were stained with $10 \mu \mathrm{g} / \mathrm{mL}$ of $4^{\prime}$,6-diamidino-2-phenolindole (Sigma-Aldrich). After incubation for 5 minutes in the dark, the cells were washed. The slides were mounted and observed under fluorescence microscope (BX50; Olympus).

\section{Tumor Formation In Vivo}

To induce orthotopic retinoblastoma, SNUOT-Rb1 cells $\left(1 \times 10^{7}\right)$ were suspended in PBS and intravitreally inoculated in the right eyes of mice, as in our previous study. ${ }^{17}$ Every week after cell inoculation, 0.1 or $5 \mu \mathrm{M}$ ATO was intravitreally injected into the right eyes. As we have previously reported, ${ }^{17}$ tumors reach maximum size between 15 and 20 days after intravitreal inoculation. Tumor development was checked by indirect ophthalmoscopic examination between 4 to 8 weeks. At 4 weeks or 8 weeks after inoculation, the mice were killed and eyes were enucleated so that we could determine whether tumors had formed.

\section{Statistical Analysis}

Statistical differences between groups were evaluated with the Student's unpaired $t$-test (two-tailed). All data provided here are mean \pm SD. $P \leq 0.05$ was considered significant.

\section{Results}

\section{Effect of ATO on Growth of Retinoblastoma Cells}

Retinoblastoma cells Y79 and SNUOT-Rb1 were treated with ATO (range, 0.1-10 $\mu \mathrm{M}$ ) for 72 hours, and cell growth was measured by MTT assay (Fig. 1). The inhibition of growth was observed in a dose-dependent manner. Although at $2 \mu \mathrm{M}$ the reductions of viable cells were more prominent in SNUOT-Rb1 cells than in Y79 cells (cell viabilities of SNUOT-Rb1 and Y79 cells were $30 \%$ and $80 \%$, respectively), a significant inhibition of growth was noted in both retinoblastoma cell lines at high concentrations $(\geq 5 \mu \mathrm{M})$.

\section{Effect of ATO on Cell Cycle Progression of Retinoblastoma Cells}

As shown in Figure 1, when ATO was at a high concentration, dead cells were easily identified, and the total number of cells was decreased. Interestingly, at a low dose of ATO $(\leq 0.5 \mu \mathrm{M})$, retinoblastoma cells showed neurite extension without significant reduction in viable cells, which were prominent in SNUOT-Rb1 (Fig. 2).

The effect of ATO in various concentrations on cell-cycle progression was validated by flow cytometry analysis. As shown in Figure 2, high-dose ATO revealed $\mathrm{G}_{2} / \mathrm{M}$ phase cellcycle arrest in a dose-dependent manner. Retinoblastoma cells underwent significant apoptosis after $G_{2} / M$ arrest with exposure to high-dose ATO. 


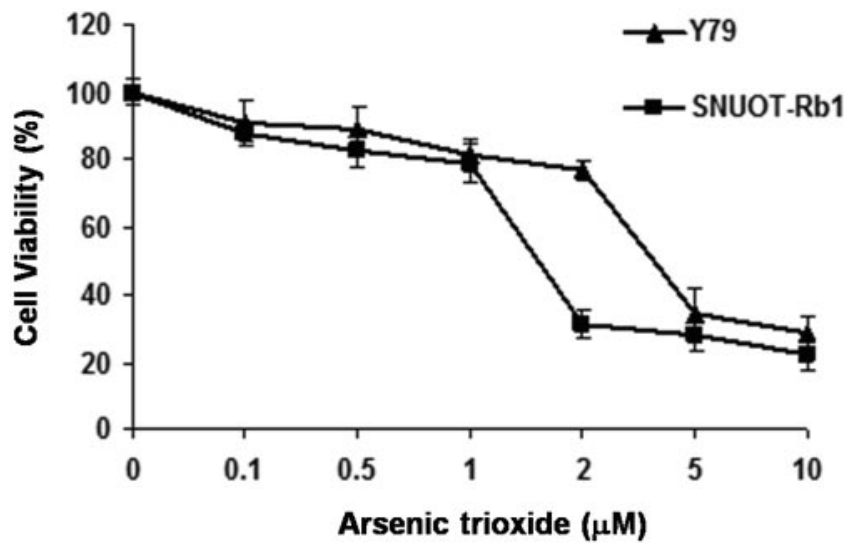

FIGURE 1. Effect of arsenic trioxide on the growth of retinoblastoma

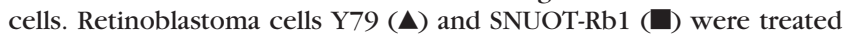
with arsenic trioxide (range, $0.1-10 \mu \mathrm{M}$ ) for 72 hours, and cell growth was measured by diphenyltetrazolium bromide assay. Data shown are the means of triplicate cultures of each cell and are presented as the percentage of control cells that received medium only. ${ }^{*} P<0.05$.

\section{Effect of Low-Dose ATO on Promotion of Differentiation in Retinoblastoma Cells}

To determine whether ATO promotes the differentiation of retinoblastoma cells at low concentrations, we assessed the expression of neurofilament and addressed the relationship with ERK1/2 activation. ${ }^{14}$ With the addition of $0.1 \mu \mathrm{M}$ ATO in SNUOT-Rb1 cells, the expression of neurofilament increased and was accompanied by the phosphorylation of ERK1/2 (Fig. $3 \mathrm{~A})$. To confirm the relationship of the ATO-induced differentiation with ERK1/2 activation, we investigated whether the inhibition of ERK1/2 blocks the differentiation of retinoblastoma cells. Cotreatment of SNUOT-Rb1 cells with $50 \mu \mathrm{M}$ PD98059, a specific inhibitor of mitogen-activated protein kinase-1, at $0.1 \mu \mathrm{M}$ ATO inhibited the phosphorylation of ERK1/2 and the expression of neurofilament (Fig. 3A), which was characterized by the morphologic changes of neurite extensions (Fig. 3B).

\section{Effect of High-Dose ATO on Induction of Apoptosis in Retinoblastoma Cells}

Because ATO initiates the apoptotic process by oxidative damage, ${ }^{12-14}$ we investigated ATO-induced $\mathrm{H}_{2} \mathrm{O}_{2}$ production using the cell-permeable fluorescent dye $2^{\prime}, 7^{\prime}$-DCFH-DA. The intensity of the mean oxidized dichlorofluorescein peak was increased by 4.7 -fold compared with study control cells after 5 $\mu \mathrm{M}$ ATO was added to SNUOT-Rb1 cells, which was significantly suppressed by concurrent treatment with $10 \mathrm{mM}$ NAC, a ROS inhibitor, as noted in our previous report ${ }^{14}$ (Fig. 4A). To validate the relationship of ATO-induced $\mathrm{H}_{2} \mathrm{O}_{2}$ production with caspase-3-dependent apoptosis, ${ }^{14}$ cleavage of caspase-3 was assessed in SNUOT-Rb1 cells. Cleavage of caspase-3 was

\section{Arsenic trioxide $(\mu \mathrm{M})$}

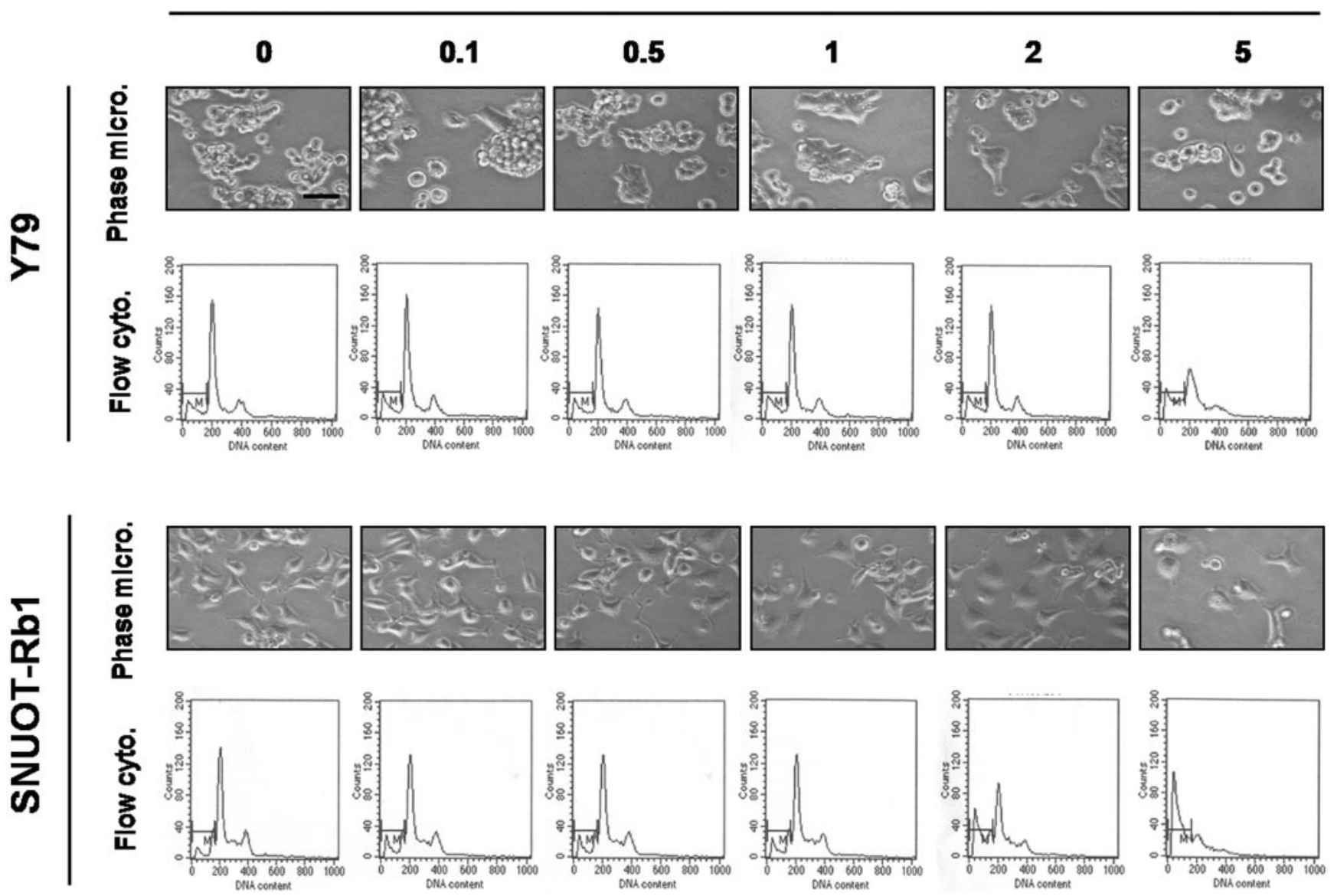

FIGURE 2. Effect of arsenic trioxide on cell-cycle progression of retinoblastoma cells. Retinoblastoma cells Y79 and SNUOT-Rb1 were treated with various concentrations of arsenic trioxide (range, 0.1-5 $\mu \mathrm{M}$ ). Cultured tumor cells were observed under a phase-contrast microscope. For cell-cycle analysis, the DNA histograms (insets) were determined by flow cytometry analysis. Data are representative of at least three independent experiments per cell line. Flow cyto, flow cytometry; Phase micro, phase-contrast microscopy. Scale bars, $50 \mu \mathrm{m}$. 
A

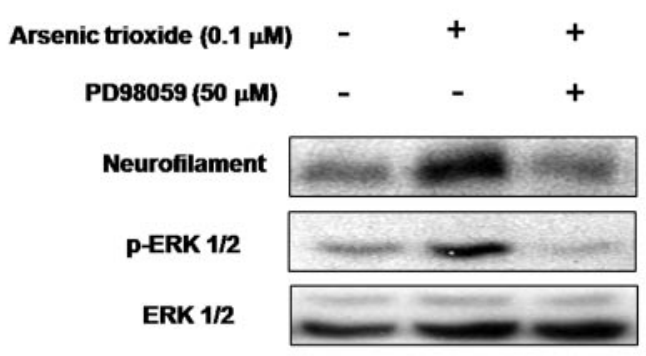

B

\section{Arsenic trioxide (0.1 $\mu \mathrm{M})$ PD98059 (50 $\mu \mathrm{M})$}

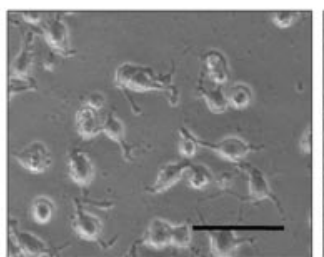

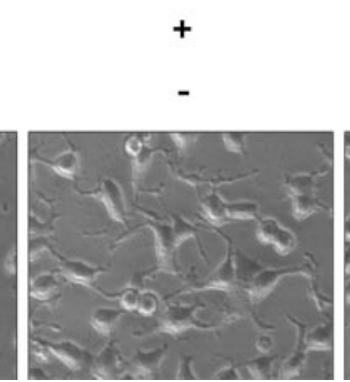

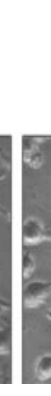

Figure 3. Effect of low-dose arsenic trioxide on the promotion of differentiation in retinoblastoma cells. SNUOT-Rb1 cells were treated with $0.1 \mu \mathrm{M}$ ATO alone or in combination with $50 \mu \mathrm{M}$ PD98059. (A) Neurofilament, ERK1/2, and phosphorERK1/2 (p-ERK 1/2) were detected by Western blot analysis. (B) Neuronal differentiation was addressed by the morphologic changes of neurite extensions. Data are representative of at least three independent experiments. Scale bars, $50 \mu \mathrm{m}$. induced by treatment with $5 \mu \mathrm{M}$ ATO, which was blocked after treatment with $10 \mathrm{mM}$ NAC (Fig. 4B). Compared with no fragmented DNA in study control cells, many strong fluorescent spots, indicating apoptotic bodies, were detected by DAPI staining of SNUOT-Rb1 cells treated with $5 \mu \mathrm{M}$ ATO and were almost completely abrogated by $10 \mathrm{mM}$ NAC (Fig. 4C).

\section{Effect of ATO on Tumor Formation In Vivo}

To assess the effect of ATO on tumor formation, we intravitreally injected 0.1 or $5 \mu \mathrm{M}$ ATO after the inoculation of cells. As shown in Table 1, injection of SNUOT-Rb1 cells generated tumors in all mice, whereas with $0.1 \mu \mathrm{M}$ ATO, the tumor developed in 2 of 8 mice at 4 weeks and in 3 of 8 mice at 8 weeks. However, with $5 \mu \mathrm{M}$ ATO, tumors were induced in 1 of 8 mice at 4 weeks and at 8 weeks. Low-dose ATO reduced tumorigenesis, but not as much as high-dose ATO. The retina without tumor was of normal thickness, and all retinal layers were clear without any inflammatory cells in the vitreous, retina, or choroid.

\section{Discussion}

Retinoblastoma is the most common malignant tumor of the retina and is an aggressive tumor that can lead to the loss of vision, loss of the eye, and, in extreme cases, to death. Recently, conducting chemotherapy in conjunction with focal therapies has been investigated. ${ }^{3,4}$ Several agents, such as vincristine, cyclophosphamide, doxorubicin, epipodophyllotoxins, and platinum-based products, have been effective in the reduction of retinoblastoma. ${ }^{3-5}$ Despite advances in therapy, retinoblastoma remains a sight- and life-threatening ocular malignancy throughout the world. Moreover, alternative chemotherapeutic combinations have not yet been identified.
A
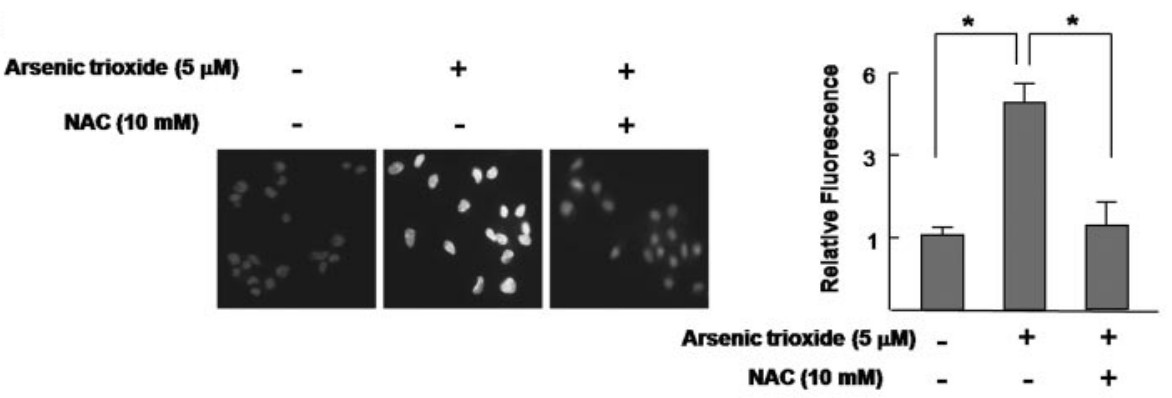

B

C

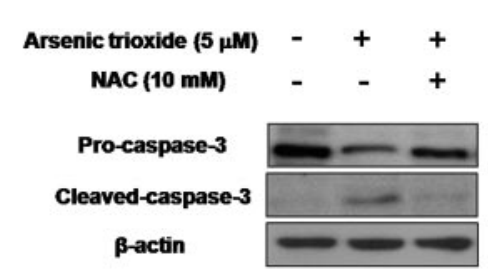

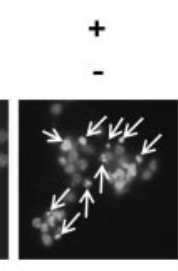

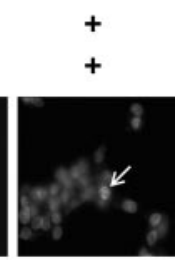

FIGURE 4. Effect of high-dose arsenic trioxide on the induction of apoptosis in retinoblastoma cells. SNUOT-Rb1 cells were treated with $5 \mu \mathrm{M}$ ATO alone or combination with $10 \mathrm{mM}$ NAC. (A) For measuring $\mathrm{H}_{2} \mathrm{O}_{2}$ production, the cells were labeled with $2^{\prime}, 7^{\prime}$ dichlorofluorescein diacetate, which was measured with fluorescence microscopy. Quantitative analysis was performed by measuring the fluorescence intensity relative to the study control cells. Each value represents the mean $( \pm \mathrm{SD})$ of three independent experiments, each performed in triplicate $\left({ }^{*} P<0.05\right)$. (B) Procaspase- 3 and caspase-3 were detected by Western blot analysis. Data are representative of at least three independent experiments. (C) Cell viability was measured using 4',6-diamidino-2-phenolindole staining. Arrows: Apoptotic nuclei. Data are representative of at least three independent experiments. 
TABle 1. Effect of Arsenic Trioxide on Tumor Formation In Vivo

\begin{tabular}{lcc}
\hline & 4 Weeks & 8 Weeks \\
\hline SNUOT-Rb1 $\left(1 \times 10^{7}\right)^{*}$ & $8 / 8$ & $8 / 8$ \\
SNUOT with $0.1 \mu \mathrm{M}$ ATO $\dagger$ & $2 / 8 \ddagger$ & $3 / 8 \ddagger$ \\
SNUOT with $5 \mu \mathrm{m}$ ATO† & $1 / 8 \neq$ & $1 / 8 \ddagger$ \\
\hline
\end{tabular}

* SNUOT-Rb1 cells $\left(1 \times 10^{7}\right)$ were intravitrcally inoculated into the right eyes of mice.

t $0.1 \mu \mathrm{M}$ ATO or $5 \mu \mathrm{M}$ ATO was intravitreally injected into the right eyes every week after inoculation of cells.

$$
\ddagger P<0.05
$$

ATO is an old drug, the efficacy of which has been established in patients with APL by the promotion of tumor cell differentiation at low concentrations and by the induction of apoptosis at relatively high concentrations.9,10,12,13 Interestingly, ATO can overcome even conventional drug resistance in APL ${ }^{9}$ and multiple myeloma. ${ }^{18,19}$ In addition, the data from our group showed that by inducing the differentiation or apoptosis of cells, ATO determines the fate of neuroblastoma cells in vitro, depending on its concentrations. ${ }^{14}$ Considering that retinoblastoma shares similar characteristics with neuroblastoma, ${ }^{15,16}$ we sought to demonstrate the antitumor activity of ATO at different concentrations on retinoblastoma cell lines and tumor formation in vivo. Retinoblastoma cells clearly showed morphologic and biological characteristics of neuronal differentiation by low-dose ATO, which was concordant with our previous results. ${ }^{14}$ However, this finding is different from those of a previous study, ${ }^{20}$ possibly because of the cell lines' unique abilities to differentiate. We also found that ERK1/2 is an important component of ATO-induced differentiation of retinoblastoma cells.

Oxidative damage is critical to the ATO-induced apoptotic process, which is associated with the generation of ROS and is accompanied by subsequent accumulation of $\mathrm{H}_{2} \mathrm{O}_{2} \cdot{ }^{9,10,14,20,21}$ ROS oxidizes lipids in the membranes of mitochondria and stimulates the release of cytochrome $\mathrm{C}$, followed by caspase activation. $^{22}$ We demonstrated that ATO initiates the caspase3 - dependent apoptotic process by $\mathrm{H}_{2} \mathrm{O}_{2}$ production that was blocked by NAC treatment. NAC treatment can block ATOinitiated changes in the cellular redox state in caspase-dependent and caspase-independent cytotoxicity. ${ }^{21}$ Especially important is that NAC increases the synthesis of glutathione, a critical regulator of the cellular redox state in ATO-induced cytotoxicity. ${ }^{9}$ The inhibition of ATO-induced $\mathrm{H}_{2} \mathrm{O}_{2}$ generation and caspase- 3 cleavage by NAC treatment demonstrates that the cytotoxicity of ATO at high concentrations is largely dependent on the generation of ROS.

Our study is the first investigation of the antitumor effects of $\mathrm{As}_{2} \mathrm{O}_{3}$ in retinoblastoma cells and tumor formation in vivo. We found that ATO differentially affects the biology of retinoblastoma cells by promoting differentiation and inducing apoptosis, depending on its concentrations. With treatment with low-dose ATO, the expression of neurofilament increased and was accompanied by the phosphorylation of ERK1/2, whereas high-dose ATO increased $\mathrm{H}_{2} \mathrm{O}_{2}$ production and induced the cleavage of caspase- 3 . Moreover, we demonstrated the inhibitory activity of ATO in retinoblastoma formation in vivo. Interestingly, even low-dose ATO reduced tumorigenesis, but not as much as high-dose ATO. This result is supported by the fact that apoptosis and growth inhibition occur at lower ATO concentrations in APL cells, indicating the cells' increased sensitivity to the apoptotic effects of ATO. ${ }^{9}$ Therefore, our results strongly suggest that ATO may be used as an effective alternative therapy for retinoblastoma and may be extended to the treatment of childhood tumors of the nervous system that originate from neural progenitor cells.

\section{References}

1. Abramson DH, Schefler AC. Update on retinoblastoma. Retina. 2004;24(6):828-848.

2. Chintagumpala M, Chevez-Barrios P, Paysse EA, Plon SE, Hurwitz R. Retinoblastoma: review of current management. Oncologist. 2007;12(10):1237-1246.

3. Beck MN, Balmer A, Dessing C, Pica A, Munier F. First-line chemotherapy with local treatment can prevent external-beam irradiation and enucleation in low-stage intraocular retinoblastoma. $J$ Clin Oncol. 2000;18(5):2881-2887.

4. Kim JH, Yu YS, Khwarg SI, Choi HS, Shin HY, Ahn HS. Clinical result of prolonged primary chemotherapy in retinoblastoma patients. Korean J Ophthalmol. 2003;17(1):35- 43.

5. Shields CL, Shields JA, De Potter P. New treatment modalities for retinoblastoma. Curr Opin Ophthalmol. 1996;7(3):20-26.

6. Nishimura S, Sato T, Ueda H, Ueda K. Acute myeloblastic leukemia as a second malignancy in a patient with hereditary retinoblastoma. J Clin Oncol. 2001;19(21):4182-4183.

7. Yoon CY, Shim YJ, Kim EH, et al. Renal cell carcinoma does not express argininosuccinate synthetase and is highly sensitive to arginine deprivation via arginine deiminase. Int J Cancer. 2007; 120:897-905

8. Kim JH, Kim JH, Yu YS, Kim DH, Min BH, Kim KW. Anti-tumor activity of arginine deiminase via arginine deprivation in retinoblastoma. Oncol Rep. 2007;18(6):1373-1377.

9. Niu C, Yan H, Yu T, et al. Studies on treatment of acute promyelocytic leukemia with arsenic trioxide: remission induction, follow-up, and molecular monitoring in 11 newly diagnosed and 47 relapsed acute promyelocytic leukemia patients. Blood. 1999; 94(10):3315-3324.

10. Miller WH Jr, Schipper HM, Lee JS, Singer J, Waxman S. Mechanisms of action of arsenic trioxide. Cancer Res. 2002;62(14):38933903.

11. Murgo AJ. Clinical trials of arsenic trioxide in hematologic and solid tumors: overview of the National Cancer Institute Cooperative Research and Development Studies. Oncologist. 2001;6(suppl 2):22-28.

12. Chen GQ, Shi XG, Tang W, et al. Use of arsenic trioxide $\left(\mathrm{As}_{2} \mathrm{O}_{3}\right)$ in the treatment of acute promyelocytic leukemia (APL), I: $\mathrm{As}_{2} \mathrm{O}_{3}$ exerts dose-dependent dual effects on APL cells. Blood. 1997; 89(9):3345-3353.

13. Sordet O, Rébé C, Leroy I, et al. Mitochondria-targeting drugs arsenic trioxide and lonidamine bypass the resistance of TPAdifferentiated leukemic cells to apoptosis. Blood. 2001;97(12): 3931-3940.

14. Jung HS, Kim HS, Lee MJ, et al. Arsenic trioxide concentration determines the fate of Ewing's sarcoma family tumors and neuroblastoma cells in vitro. FEBS Lett. 2006;580(20):4969-4975.

15. Becker LE, Hinton D. Primitive neuroectodermal tumors of the central nervous system. Hum Pathol. 1983;14(6):538-550.

16. Dyer MA. Mouse models of childhood cancer of the nervous system. J Clin Pathol. 2004;57(6):561-576.

17. Kim JH, Kim JH, Yu YS, Kim DH, Kim CJ, Kim KW. Establishment and characterization of a novel, spontaneously immortalized retinoblastoma cell line with adherent growth. Int J Oncol. 2007; 31(3):585-592.

18. Hayashi T, Hideshima T, Akiyama M, et al. Arsenic trioxide inhibits growth of human multiple myeloma cells in the bone marrow microenvironment. Mol Cancer Ther. 2002;1(10):851-860.

19. McCafferty-Grad J, Bahlis NJ, Krett N, et al. Arsenic trioxide uses caspase-dependent and caspase-independent death pathways in myeloma cells. Mol Cancer Ther. 2003;2(11):1155-1164.

20. Ora I, Bondesson L, Jönsson C, et al. Arsenic trioxide inhibits neuroblastoma growth in vivo and promotes apoptotic cell death in vitro. Biochem Biophys Res Commun. 2002;277(1):179-185.

21. Chen YC, Lin-Shiau SY, Lin JK. Involvement of reactive oxygen species and caspase 3 activation in arsenite-induced apoptosis. J Cell Physiol. 1998;177(2):324-333.

22. Joza N, Susin SA, Daugas E, et al. Essential role of the mitochondrial apoptosis-inducing factor in programmed cell death. Nature. 2001;410(6828):549-554. 